\title{
LA CRISIS Y LA DECADENCIA CIVILIZATORIA: EL CAPITAL Y LAS MISTIFICACIONES SISTÉMICAS DE LA COVID-19
}

\section{CRISIS AND CIVILIZATIONAL DECLINE: CAPITAL AND THE SYSTEMIC MYSTIFICATIONS OF COVID-19}

\author{
Camilo Valqui Cachi ${ }^{1}$, Irma Romero Adame ${ }^{2}$ \\ 1,2 - Universidad Autónoma de Guerrero (UAGro), Guerrero, México \\ 1. Email: drccvc@hotmail.com ORCID: https://orcid.org/0000-0003-3064-1602 \\ 2. Email: irmaradumilvag@hotmail.com ORCID: https://orcid.org/0000-0002-2317-5466
}

Recibido: 04/06/2021 Aceptado: 09/01/2022

Cómo Citar: Valqui Cachi, C., \& Romero Adame, I. (2022). Crisis y decadencia civilizatoria: El Capital y las mistificaciones sistémicas de la Covid-19. Dialektika: Revista De Investigación Filosófica Y Teoría Social, 4(9), 47-56. https://doi.org/10.51528/ $\underline{\text { dk.vol4.id58 }}$

\begin{abstract}
Resumen:
El presente trabajo epistémico se orienta a desentrañar la pandemia Covid-19, a partir de someter a crítica la esencia, dialéctica y complejidad del capitalismo, productor también de pandemias sistémicas y cuya civilización enfrenta no únicamente una crisis mundial sino también registra una decadencia que desborda barbarie y pone en relieve los límites históricos del capital. En este contexto es fundamental tratar la etiología, génesis, metamorfosis, efectos y alternativas de solución de la Covid-19, así como diluir las falacias que encarnan sus correspondientes mistificaciones sistémicas, para eludir el análisis de su razón ser. Nuestro objetivo en este sentido es contribuir a la construcción de conciencias desalienadas que asuman la crítica teórica y la crítica práctica al capital rumbo hacia una comunidad libre de la Humanidad y la Madre Naturaleza.
\end{abstract}

Palabras clave: crisis, capital, sistema, la Covid-19.

\begin{abstract}
:
The present paper is oriented to unravel the Covid-19 pandemic, starting from submitting to critique the essence, dialectics and complexity of capitalism, producer also of systemic pandemics and whose civilization faces not only a world crisis but also registers a decline that overflows barbarism and highlights the historical limits of capital. In this context it is fundamental to deal with the etiology, genesis, metamorphosis, effects and alternative solutions of Covid-19, as well as to dilute the fallacies embodied in its corresponding systemic mystifications, in order to avoid the analysis of its raison d'être. Our objective in this sense is to contribute to the construction of unalienated consciences that assume the theoretical critique and the practical critique of capital towards a free community of humanity and Mother Nature.
\end{abstract}

Keywords: crisis, capital, system, Covid-19. 
En el contexto del Siglo XXI, signado por la crisis mundial de la moderna civilización del capital que sigue desbordando barbarie (Morin, 2005) como rasgo relevante de sus límites históricos, revelando además su decadencia, brota la pandemia Covid-19, desde las entrañas del capital productor de cotidianas pandemias sistémicas.

Partir de esta compleja realidad es la premisa fundamental (Corona y Rodolfo, 2012) para realizar una investigación crítica y de toda lectura epistémica de la Covid-19, capaz de someter a crítica la especulación trivial, el desliz metafísico, la simplificación cientificista y las dominantes mistificaciones sobre esta pandemia, generalmente funcionales a los procesos de acumulación de capital del Siglo XXI.

Por ende, es fundamental someter a crítica radical las falacias, las fantasías, la seudociencia y las mistificaciones burguesas en torno a la Covid-19, como las que siguen:

1. La Covid-19, es un producto de la Naturaleza, es un desastre natural y un fenómeno biológico.

2. Es una venganza y una guerra de la Naturaleza contra los seres humanos.

3. Es un problema puramente médico y técnico-administrativo.

Todo lo contrario, la Covid-19, es un complejo fenómeno, un entramado de relaciones humanas y naturales, una urdimbre de elementos, factores, procesos y circunstancias tanto históricas como concretas. La complejidad de la Covid-19, no puede descifrar haciendo abstracción del sistema capitalista.
Examinar la Covid-19, desde la perspectiva de la complejidad, es como sostiene Karl Marx, descubrirla y asumirla como el resultado de "múltiples determinaciones" (Marx, 2007) en su etiología, génesis, metamorfosis, efectos y alternativas de solución.

En consecuencia, su tratamiento y eliminación, conllevan la misma complejidad, simplificarla es propio del cretinismo cientificista y del cinismo sistémico, inherentes a los procesos sistémicos de acumulación ideológica.

La Covid-19, es un complejo problema generado por el sistema capitalista, productor de estas pandemias imbricadas a su vez a las cotidianas pandemias sistémicas que plagan y devastan no solo a la Humanidad, sino también a la Naturaleza, desde su instauración por la vía de la violencia, concretada en el violento despojo que sufren grandes masas humanas de sus medios de subsistencia y de producción, transformadas en multitudes de clases proletarias arrojadas al nuevo mercado de trabajo, (Marx, 2013) para vender lo único que les deja el capital: sus fuerzas de trabajo, devenidas mercancías, primero y enseguida una forma de capital, el capital variable, el capital vivo.

Así nació el capitalismo, en la entrañas de la acumulación originaria y en las profundidades siniestras de sus procesos de acumulación moderna, siempre centrándose en la privatización y mercantilización de todo, en el despojo territorial de las Comunidades Originarias, en los nuevos procesos de acumulación primitiva de capital vía los extractivismos y acumulación militarizada de capital, (López y Rivas, 2021) en la subasta de países enteros, en el parasitismo del capital financiero, en el expolio colonial a través de 
deuda, en las actuales recolonizaciones integrales y en la devastación total de la Naturaleza.

Esta violencia del capital, es una verdadera potencia económica (op.cit.) que no agota su truculenta dialéctica, sigue llegando aún a este mundo: "[...] chorreando lodo y sangre por todos los poros, desde la cabeza a los pies", (op.cit.) no ha cambiado su esencia, pese a las profundas reestructuraciones en la dialéctica del capital y del trabajo.

$\mathrm{Y}$ esta potencia económica política devastadora de la Humanidad y la Naturaleza, en última instancia lo decide todo, lo devora todo, lo domina todo, lo destruye todo, porque es el sustento de todos los poderes y de todas las violencias instrumentales, a pesar de que en el curso de sus metamorfosis oculta su naturaleza de clase enajenándose del capital y emergiendo como una supuesta condición humana y un rasgo esencial de la Naturaleza, en la conciencia alienada de sus propias víctimas, los trabajadores y pueblos del mundo.

Sin embargo, Karl Marx, había previsto muy temprano, que el capitalismo a nivel planetario no cesa en desarrollar la técnica y la combinación del proceso social de producción a expensas de la destrucción, al mismo tiempo de los dos manantiales de toda riqueza: la tierra y el trabajador, (Marx, 2016) la Humanidad y la Naturaleza.

Karl Marx, a la sazón puso al desnudo la esencia devastadora de la acumulación de capital en todo el mundo, el capital existe a expensas de la destrucción de la vida.

La crítica radical de Fidel Castro, en la Cumbre de la Tierra en 1992, confirma la genial previsión de Karl Marx, al decir:

Una importante especie biológica está en riesgo de desaparecer por la rápida y progresiva liquidación de sus condiciones naturales de vida: el hombre. Ahora tomamos conciencia de este problema cuando casi es tarde para impedirlo. Es necesario señalar que las sociedades desarrolladas son responsables fundamentales de la atroz destrucción del medio ambiente. Ellas nacieron de las antiguas metrópolis coloniales y de políticas imperiales que, a su vez, engendraron el atraso y la pobreza que hoy azotan a la inmensa mayoría de la humanidad. Con el solo el 20 por ciento de la población mundial, ellas consumen las dos terceras partes de los metales y las tres cuartas partes de la energía que se produce en el mundo. Han envenenado los mares y ríos, han contaminado el aire, han debilitado y perforado la capa de ozono, han saturado la atmósfera de gases que alteran las condiciones climáticas con efectos catastróficos que ya empezamos a padecer (Castro, 1992)

Paradójicamente, pese a esta cruda realidad, la truculenta violencia del capital, histórica y concreta, no solo se transfigura sino también se oculta en la densa niebla fenoménica de la frivolidad capitalista, incluso se desvanece en la conciencia social alienada, prisionera de las feroces esclavitudes modernas que imperan y bajo el incesante azote de la industria ideológica que mistifica la realidad y enajena a grandes masas humanas, asimilándolas, domesticándolas, sometiéndolas y haciéndolas adictas al complejo poder del capital.

En este contexto histórico y concreto, Nuestra América, fue plagada de violencias y miserias por el imperialismo yanqui y por las oligarquías locales a su servicio, cuyas pandemias sistémicas 
produjeron y reprodujeron su condición colonial y neocolonial siendo a la vez devastada por las pandemias neoliberales implantadas en la región desde el último cuarto del Siglo XX, incubando hasta el 2020, más de 214,7 millones de pobres, 83,4 millones de personas en extrema pobreza y 44 millones de desocupados, según los Informes de la CEPAL. (CEPAL, 2020)

La sistémica Covid-19 ha centuplicado estas truculencias capitalistas al matar principalmente a los excluidos y oprimidos de siempre los pobres sean niños, ancianos, jóvenes, pueblos originarios, campesinos, desempleados, migrantes, afro descendientes, trabajadores informales $y$ especialmente a las mujeres. (Artous, 2021)

$\mathrm{Al}$ respecto un Informe de la CEPAL, expresa:

La pandemia irrumpe en un escenario económico, social y político complejo: bajo crecimiento, aumento de la pobreza y crecientes tensiones sociales. Además, pone al desnudo las desigualdades estructurales que caracterizan a las sociedades latinoamericanas [...]. La pandemia ha evidenciado y exacerbado las grandes brechas estructurales de la región y, en la actualidad, se vive un momento de elevada incertidumbre en la que aún no están delineadas ni la forma ni la velocidad de la salida de la crisis. (CEPAL, 2021)

Asimismo, Nuestra América ha sido convertida en un codiciado botín de las disputas coloniales entre las fracciones imperialistas.

Consecuentemente hoy, las burguesías del capitalismo imperialista en su codicia insaciable de plusvalía y en sus locas pugnas geopolíticas usufructúan en lo esencial a la Covid-19, para encubrir las crisis recurrentes del orden del capital, así como para ocultar, justificar, naturalizar y perpetuar las viejas relaciones capitalistas de explotación y dominio de espectro total, como también para intensificar la imperialización neofascista y anticomunista, contra las luchas de los trabajadores y pueblos, contra los movimientos sociales, procesos revolucionarios, democráticos y populares del orbe.

Y a través de sus científicos, tecnócratas, políticos, médicos, ideólogos, comunicadores, educadores, académicos, abogados, cuerpos de seguridad, servicios de inteligencia, ejércitos y particularmente de sus big tech, han tejido un claroscuro en torno a la Covid-19 funcional al capital, transfigurándola indistintamente en:

1. Instrumento de amplio espectro para mistificar la crisis capitalista mundial, la decadencia y la descomposición civilizatoria que desborda fascismo, barbarie mundial. (Fernandes, 2021)

2. Ideología para velar las pandemias sistémicas que produce el capital, como: la pobreza, la desigualdad, las violencias, el racismo, el hambre, el desempleo, las guerras, el terrorismo de Estado, la inseguridad, el narcotráfico, las recolonizaciones, la trata de personas, el exterminio de migrantes, los feminicidios, la imperialización y las riñas estratégicas entre las fracciones imperialistas por el dominio planetario de espectro total, las cruzadas anticomunistas y fascistoide y las enajenaciones, pandemias condensadas en la devastación de los seres humanos y de la Naturaleza, concretada en el ecocidio.

3. Fetiche militar y por ende enemigo invisible con astucias sujetas a cierta lógica de guerra irregular para justificar y franquear la militarización de la vida social y el 
establecimiento de lo que Carlos Fazio denomina sistema totalitarismo tecnosanitario-plutocrático. (Fazio, 2021)

4. Tapadera del terrorismo trasnacional de Estado contra fuerzas y movimientos sociales en el mundo, potencialmente insurgentes, que justifiquen la imposición de estados de sitios, de excepción, autoritarismo y políticas terroristas de carácter fascista y anticomunista como se ha venido registrando en EE.UU., Colombia, Brasil, Chile, Bolivia con el golpe de Estado y Perú en su reciente proceso electoral.

5. Camuflaje imperialista geopolítico y contrainsurgente para el espionaje, el control, la vigilancia digital y la liquidación de organizaciones, dirigentes y luchadores insurgentes, de movimientos sociales $y$ antisistémicos, de pensadores marxistas, intelectuales críticos, partidos de izquierda y fuerzas democráticas y populares. Como también para la enajenación y la administración digital de grandes masas humanas, universidades, escuelas y diversas organizaciones de los pueblos y de los trabajadores.

Todo esto evidencia el universo truculento de la civilización capitalista que implantó la moderna esclavitud asalariada, la moderna esclavitud de la Madre Naturaleza y la moderna esclavitud de la enajenación, transformó orgánicamente a la fuerza de trabajo y a la Madre Naturaleza en mercancías y también en formas de capital y que por lo tanto privatiza, mercantiliza y enajena todo.

Este es el capital que ha perpetrado y perpetra las quiebras tectónicas de la compleja unidad dialéctica de los seres humanos entre sí y de éstos, con la Madre Naturaleza.

Aquí estriba en última instancia la raíz, la esencia de la Covid-19 y de todas las pandemias sistémicas, imposible de resolverlas si no se desentraña su razón de ser, excepto administrarlas, regularlas y paliarlas.

Mientras el capital seguirá produciendo y reproduciendo sin fin, la devastación de los ecosistemas, (Mongabay Latam, 2020) condensada en el ecocidio, que es la destrucción mundial de la biosfera y con ella la extinción de las especies.

"La economía capitalista globalizada exacerba estos problemas al destruir toda la biósfera, infligiendo graves e irreparables daños a un intrincado sistema que sustenta la vida". (Broswinmmer, 2005)

El ecocidio fragua las causas esenciales $y$ entrelaza epidemias y pandemias en todo el mundo, como la Covid-19, cuya complejidad a su vez articula:

1. La pérdida de biodiversidad, la deforestación, los incendios, tala y la pérdida de especies, aviva la propagación de pandemias esto lo conocen muy bien quienes se dedican a la ecología de las enfermedades.

2. Las altas tasas de contaminación con altas tasas de emisiones globales de dióxido de carbono (CO2), se corresponden con altas tasas de mortalidad. Se ha probado que la contaminación del aire hace, que más personas sean susceptibles de enfermedades respiratorias. En un ambiente contaminado sobreviven las nuevas bacterias.

3. El cambio climático, más mortal que el Covid-19, tiene un efecto demoledor $y$ 
multiplicador de amenazas que agravan muchos problemas, el incremento irregular de las temperaturas a nivel local y global inciden de modo decisivo en el desarrollo de bacterias, como ocurre con los derretimientos de hielo descubriendo virus letales alojados en los casquetes helados por el lapso de 15,000 años de antigüedad.

4. El tráfico de la flora y particularmente de la fauna silvestre, que constituye el cuarto comercio ilegal del mundo, después de las drogas, la trata de personas, la falsificación y las armas; así como la esclavitud, dolor y exterminio de las personas animales.

5. La producción industrial de los alimentos, la plaga de los agronegocios, de los agro tóxicos, de los megaproyectos, los proyectos de carácter ecocidíco de reordenamiento territorial IIRSA (Iniciativa para la integración de la infraestructura regional Sur American); (Farías y David, 2021) de los fármacos que fijan enfermedades, del extractivismo colonial que devora biodiversidad y que fomenta las economías de enclave y que desarrollan tardíamente agresivos procesos de acumulación de capital transnacional por la vía de desposesión militarizada y del ejercicio de la necropolítica (López y Rivas, 2020), del sistema alimentario agroindustrial y de los transgénicos (Turrent Fernández, 2016) industrializados impulsada por la llamada revolución verde (Brito, 2021) que tiende a patentizar la propia Madre Naturaleza destruyendo incluso las semillas originarias cultivadas por miles de años por generaciones de campesinos y liquidando así la agrobiodiversidad de las comunidades ancestrales.
(Molina Cañadas, 2020). Estas transnacionales también monopolizan la venta de fertilizantes, equipos digitales y maquinaria agrícola. (López Blanch, 2020) La Covid-19, ha centuplicado sus ganancias monopólicas destruyendo vida humana y natural, así como monopolizan la producción y mercadeo de las epidemias y pandemias, que son sus áreas de alta rentabilidad.

6. Las guerras geopolíticas de intensidad diferenciada, local, regional y mundial en el gran tablero de ajedrez global, (He Zhao, 2020) donde las potencias imperialistas $y$ particularmente EE.UU., utilizaron y utilizan armas de exterminio masivo contra la humanidad y la Madre Naturaleza. Allí están las pruebas eternas de Hiroshima, Nagasaki, Vietnam, Corea, Irak, Afganistán, Libia, Siria, Palestina, Irán, Yemen, Somalia, Cuba, Venezuela, Nicaragua, Colombia, Perú, el Cono Sur y otras regiones del mundo. Las armas biológicas, químicas, nucleares, sísmicas, genómicas, electrónicas, cibernéticas y ambientales, que abarrotan los complejos militares industriales de las fracciones imperialistas, así como sus respectivos ensayos han devastado, devastan y devastarán seres humanos y a la Madre Naturaleza, en todos los escenarios de guerra del mundo, en el proceso de establecer la "estratégica arquitectura global" (Jalife-Rahme, 2019) . En este campo la gran miseria del capitalismo contra la Humanidad y la Madre Naturaleza fue consumada por el imperialismo de los EE.UU. en Vietnam, Irak, Afganistán, Libia, Siria, Palestina, Ucrania, el Norte de África y Cuba y contra otros pueblos anti-imperialistas. 
Guerras además avaladas por la complicidad de la propia Organización de las Naciones Unidas. La exacerbada carrera armamentista capitalista ha conllevado asimismo ensayos y experimentos con la Madre Naturaleza, con los seres humanos y con los animales.

7. Pero, además, el Covid-19, inscrito en la encarnizada lucha geoestratégica por el nuevo reparto del planeta de la nueva guerra fría (EE.UU., China y Rusia), es también una compleja bioarma, en cuya producción y uso masivo, EE.UU. Está a la cabeza de las potenciales en conflicto. Tesis sin duda muy discutible, pero seguramente de gran peso epistémico histórico y concreto.

8. Imbricado con este supuesto, se ha formulado otro supuesto, que define al Covid-19, como instrumento de una profilaxis neomalthusiana de control demográfico, una especie de darwinismo social para desaguar la "sobrepoblación" implementada por parte de los sectores más reaccionarios del gran capital mundial, interesados en hacer una limpieza sistémica desechando la población mundial superflua que genera graves problema sociales y además, incapaz de producir plusvalía, considerando en esta categoría a las personas mayores, a los jubilados, pobres, migrantes, pueblos originarios, afro descendientes, lumpen proletarios periféricos, drogadictos y personas con discapacidad, que además constituyen potenciales fuentes de la subversión antisistémica, peligro que las oligarquías del mundo se proponen conjurar, reforzar y refundar al sistema capitalista mundial que a pesar de ellas desborda barbarie y decadencia civilizatorias.
Como se puede advertir, la experiencia histórica y concreta demuestra que el capitalismo destruye Humanidad y Madre Naturaleza por codicia, destruye la vida por codicia y se realiza en la muerte. La civilización del capital desprecia la Madre Naturaleza, (Villasante Cervello, 2020) es una fragua de muerte.

Consecuentemente, el capitalismo es un sistema que ha provocado la Covid-19, al violar diariamente la naturaleza y las formas de vida humanas, (Jaén, 2020).

Se coincide con Enrique Leff cuando sostiene: "El capitalismo ha engullido al mundo, lo ha enmascarado y velado en su propia imagen, [...]. La acumulación de capital, las tasas de explotación de los recursos y los patrones dominantes de consumo han llegado a sobrepasar la capacidad de carga y dilución de los ecosistemas, llevando a formas y ritmos sin precedentes de degradación ecológica, de extinción biológica, de erosión de suelos y destrucción de biodiversidad”. (Leff, 2004)

En la misma línea James O'Connor, afirma: “El desarrollo capitalista desigual, [...] tiende a causar contaminación masiva en zonas industriales y degradación masiva de tierra, suelos, vida vegetal y demás en zonas productoras de materias primas. También provoca sobrepoblación (en el sentido de sobre proletarización y pobreza generalizada) en las zonas subdesarrolladas, lo cual acelera la degradación de la naturaleza [...]”. (O'Connor, 2001)

La crisis permanente capitalista, reitera los límites del capital, la sobreacumulación del capital productivo y la inexorable contracción del mercado; (Chesnais, 2020) explosión de sus contradicciones antagónicas, revelando en última 
instancia la decadencia y descomposición de la civilización del capital, desbordando tres quiebras tectónicas, que entrelazadas conforman la quiebra sistémica total de la vida:

1. Quiebra de la compleja unidad dialéctica del Ser Humano

2. Quiebra de la compleja unidad dialéctica de la Madre Naturaleza, y

3. Quiebra de la compleja unidad dialéctica del Ser Humano y del Ser Naturaleza.

De esta manera la moderna civilización capitalista abisma la devastación irreversible del complejo metabolismo de la Humanidad y la Madre Naturaleza, perpetrando una hecatombe de la Vida, poniendo en relieve su decadencia y descomposición sistémica. (Valqui Cachi, 2017)

Por esto, se necesita como nunca la crítica teórica y práctica del sistema capitalista, poniendo en relieve el lado el siniestro de su razón instrumental, así como su siniestra médula antihumana y antinatural, que subyace en la enajenación humana.

Una civilización que se valoriza por igual a expensa de la vida y también en la muerte truculenta. (Valqui Cachi, 2020)

Sin embargo, una recepción ideológica y simplista de la crítica a la moderna civilización del capital podría ser para algunos o para muchos una crítica prejuiciada, porque estaría ignorando $\mathrm{y}$ negando las maravillas, las revoluciones científicas, tecnológicas, los portentosos progresos y culturales en todos ámbitos de la existencia se realizaron y se realizan en el contexto del capitalismo.

Evidentemente tal visión es ajena a la crítica formulada al capital, como sistema complejo. En este sentido, lo primero que es necesario desmontar es la falacia que atribuye al capital y al capitalismo, las maravillas, las grandes transformaciones espirituales y materiales, las revoluciones científicas, tecnológicas y culturales, cuando todo este portentoso desarrollo es obra de las fuerzas de trabajo calificado y no calificado de los proletarios, trabajadores y pueblos del mundo y de la propia Naturaleza.

No debería olvidarse jamás, que el trabajo puede existir sin capital, pero éste no podría tener vida sin el trabajo vivo.

Al respecto, Karl Marx, revela que el capital como relación social, sistema y civilización, será superado solo cuando una gran revolución se apropie de las conquistas de la época burguesa, del mercado mundial y de las modernas fuerzas productivas sometiéndolos al control de los pueblos más avanzados, solo entonces el progreso humano habrá dejado de parecerse a ese horrible ídolo pagano que solo quería beber el néctar en el cráneo del sacrificado. (Marx, s/f.)

Esta perspectiva crítica pulveriza también las quimeras cientificistas que postulan el fin del trabajo vivo y la eternidad de la inteligencia artificial.

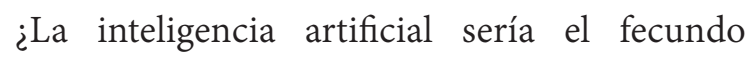
manantial de la plusvalía y por ende resucitaría al capital muerto? 


\section{REFERENCIAS}

Artous, Antoine. (4 de mayo de 2021). Opresión de la mujer y capitalismo, en https:// bit.ly/3u 8jfNC

Brito, Gabriel. (3 de mayo de 2021). Ecología social. Amayra El Khali: <Todos los instrumentos de la economía verde obedecen a la misma lógica perversa de financierización>. Recuperado en https:// bit.ly/3G6C3PL

Broswinmmer, Franz j. (2005). Ecocidio. Breve historia de la extinción en masa de las especies, Laetoli, Pamplona.

Castro, Fidel, (el 12 de junio de 1992). Discurso en Río de Janeiro en la Conferencia de Naciones Unidas sobre Medio Ambiente y Desarrollo.

CEPAL (2020). Informe de la CEPAL, 12 de mayo de 2020 .

CEPAL (2021). Claves de la CEPAL para el desarrollo, $\mathrm{N}^{\circ} 8$, marzo de 2021.

Chesnais, Francois. (19 de abril del 2020). "Situación de la economía mundial al principio de la gran recesión Covid-19", en Viento Sur.

Corona Fernández, Javier y Rodolfo Cortés del Moral (2012). (Coordinadores). Complejidad, la encrucijada del pensamiento, Porrúa.

Costa Gravas, Alberto. (27 de abril de 2021). Los bárbaros están volviendo, entrevista al Director de cine Costa-Gavras. Recuperado en https://bit.ly/3r7X1cG
Farías Delva, David Santiago. (4 de mayo de 2021). Ecología Social. IIRSA: El camuflado virus de la devastación. Recuperado en https://bit.ly/3KV9YhN

Fazio, Carlos. (3 de mayo de 2021, México). ¿Conspiparanoicos o seudociencia $\mathrm{y}$ biofascismo, en https://bit.ly/3skNY7N

Fernandes, Sabrina. (1 de mayo de 2021). Los tiempos de barbarie exigen osadía, entrevista a Michael Löwy, Recuperado en https://bit.ly/3rbHjod

He Zhao, Leo. (27 de abril de 2020). El largo juego $\mathrm{y}$ sus contradicciones. Recuperado en https://bit.ly/3HhF3Ko

Jaén, Jesús. (28 de abril de 2020). Pensamiento crítico. Salud y capital en la crisis del coronavirus (y algunas reflexiones políticas), en https://bit.ly/34nouLD

Jalife-Rahme, Alfredo (2019). Nacionalismo contra globalismo. Dicotomía del Siglo XXI antes de la inteligencia artificial, Orfilia.

Leff, Enrique (2004). Racionalidad ambiental la reapropiación social de la naturaleza, Siglo Veintiuno Editores.

López Blanch, Hedelberto. (8 de mayo de 2020). Bayer-Monsanto se lucra con la pandemia, Recuperado en https://bit.ly/ $3 \mathrm{HggZHL}$

López y Rivas, Gilberto. (15 de mayo de 2020). "Militarismo y desposesión", en La Jornada, México. 
López y Rivas, Gilberto. (30 de abril de 2021). Travesía por la vida versus acumulación militarizada, en https://bit.ly/34lTuP6

Marx, Carlos, "Futuros resultados de la dominación británica en la India", en Marx, Carlos y Federico Engels. Acerca del colonialismo, Progreso, Moscú, s/f.

Marx, Karl (2007). Elementos fundamentales para la crítica de la economía política (Grundrisse) 1857-1858, Siglo Veintiuno Editores, t. 1.

Marx, Karl (2013). El capital, Siglo Veintiuno Editores, t. I, Vol. III.

Marx, Karl (2016). El capital, Siglo Veintiuno Editores, t. I, Vol. II.

Molina Cañadas, Carmen. (2 de mayo de 2020). Política agroalimentaria para un mundo saqueado. Recuperado en https://bit.ly/ 3rdQ7m0

Mongabay Latam, (23, marzo del 2020). Coronavirus: verdades y realidad ambientales del COVID-19. Recuperado en https://bit.ly/3GcEjoo

Morin, Edgar (2005). Breve historia de la barbarie en Occidente, Paidos.

O'Connor, James (2001). Causas naturales. Ensayos de marxismo ecológico, Siglo Veintiuno Editores.

Turrent Fernández, Antonio. (11 de mayo de 2016). Transgénicos, tecnología obsoleta para el campo, en https://bit.ly/3KUVQ8s
Valqui Cachi, camilo (2017). Karl Marx. Fin del capitalismo y los tiempos del comunismo, EÖN-Universidad Autónoma de Guerrero.

Valqui Cachi, camilo (2020). Pandemia: Karl Marx todo sólido se desvanece en el aire del Siglo XXI, EÖN-Universidad Autónoma de Guerrero.

Valqui Cachi, Camilo et. al. (2014). El ecocidio del Siglo XXI. Cosmovisiones, premisas, impactos y alternativas, EÖNUniversidad Autónoma de Guerrero.

Villasante Cervello, Mariella. (30 de marzo del 2020). [SERVINDI] El coronavirus CoV-2 y su expansión mundial: un resultado de la acción humana contra el medioambiente. Recuperado en https:// bit.ly/3u8QC2T 